\title{
Pharmaceutical Properties of Marine Polyphenols: An Overview
}

\author{
Vo Thanh Sang ${ }^{1 *}$, Ngo Dai Hung², Kim Se-Kwon ${ }^{3}$ \\ 1 NTT Institute of Hi-Technology, Nguyen Tat Thanh University, Ho Chi Minh City, Vietnam. \\ 2 Faculty of Natural Sciences, Thu Dau Mot University, Thu Dau Mot City, Binh Duong Province, Vietnam. \\ 3 Department of Marine Life Science, College of Ocean Science and Technology, Korea Maritime and Ocean University, \\ Busan 606-791, Korea.
}

\begin{abstract}
Natural products are non-drug materials that have applied for prevention or treatment of health problem. The use of natural products as pharmaceutical ingredients has got much attention by consumers nowadays. Among them, marine organisms are currently considered as a huge source for the discovery of pharmaceutical agents. During the last decades, numerous novel agents have been achieved from marine organisms and many of them have potential application in pharmaceutical industry. Notably, marine algae are known to be one of the most important producers of variety of chemically active metabolites. Especially, phlorotannins, a polyphenol from brown algae, have been revealed to possess numerous biological activities such as UV-protective, anti-oxidant, anti-viral, anti-allergic, anti-cancer, anti-inflammatory, anti-diabetes, and anti-obesity activities. Therefore, phlorotannins are promising agents for development of pharmaceutical products. This contribution focuses on phlorotannins from brown algae and presents potential application in pharmaceutical field due to its biological activities and health benefit effects.
\end{abstract}

Keywords: Natural product, Pharmaceutical, Phlorotannins, Algae, Bioactivity.

\section{INTRODUCTION}

The marine environment represents approximately half of the global biodiversity. It is a rich source of structurally diverse and biologically active metabolites, which are important for the discovery of potential therapeutic agents ${ }^{1,}$ ${ }^{2}$. During the last decades, marine organisms have received much attention in screening marine natural products for their biomedical and pharmaceutical potentials $^{3-5}$. Various marine organisms such as algae, tunicates, sponges, soft

*Corresponding Author: Vo Thanh Sang, email: vtsang@ntt.edu.vn; Tel.: +84 2862717296

Vo Thanh Sang ORCID Number: 0000-0002-6726-3257

Ngo Dai Hung ORCID Number: 0000-0002-4025-1694

Kim Se-Kwon ORCID Number: 0000-0001-6507-9539

(Received 03 December 2018, accepted 15 January 2019) 
corals, bryozoans, sea slugs, mollusks, echinoderms, fishes, microorganisms, etc. have been subjected for isolation of numerous novel compounds. Consequently, numerous active agents such as lipid, protein, peptide, amino acid, neurotoxins, polysaccharides, chlorophyll, carotenoids, vitamins, minerals, and unique pigments have been discovered. Many of these substances have been demonstrated to possess interesting biological activities ${ }^{6-14}$. Notably, marine algae are known to be one of the most important producers of biomass in the marine environment. Algae are very simple chlorophyll-containing organisms composed of one cell or grouped together in colonies or as organisms with many cells ${ }^{15}$. Therefore, they vary greatly in size from unicellular of 3-10 $\mu \mathrm{m}$ to giant kelps up to 70-meter-long. Algae are identified as the microalgae which are found in both benthic and littoral habitats and also throughout the ocean waters as phytoplankton and the macroalgae (seaweeds) which occupy the littoral zone. Phytoplankton comprises diatoms, dinoflagellates, green and yellow-brown flagellates, and blue-green algae while seaweeds are classified into green algae, brown algae, and red algae. Marine algae are known to be a good source of healthy food due to their low content in lipids, high concentration in polysaccharides, natural richness in minerals, polyunsaturated fatty acids and vitamins. Especially, seaweeds are able to produce a great variety of secondary metabolites characterized by a broad spectrum of biological activities such as anti-coagulation, anti-virus, anti-oxidant, anti-allergy, anti-cancer, anti-inflammation, anti-obesity, anti-diabetes, anti-hypertension, neroprotection, and immunomodulation ${ }^{16-19}$. Therefore, marine algae are believed to be a promising source to provide not only novel biologically active substances for the development of pharmaceuticals but also essential compounds for human nutrition ${ }^{20}$.

The Phaeophyceae (brown algae) is a large group of marine multicellular algae, including various seaweeds. They play an important role in marine environments, both as food and for the habitats they form. Although the division Phaeophyta consists of 13 orders according to the classification of Bold and Wynne ${ }^{15}$, only three orders namely Laminariales, Fucales, and Dictyotales have been extensively researched for their phytochemicals. The most studied species of these orders are Laminaria, Ecklonia, Undaria, Himanthalia, Sargassum, and Dictyota. Brown seaweeds are rich in polysaccharide, polyphloroglucinol phenolic compounds, and other secondary metabolites such as terpenes, carotenoids, and oxylipins ${ }^{20}$. Notably, marine brown algae accumulate a variety of phloroglucinol-based polyphenols, as phlorotannins. These pholorotannins consist of phloroglucinol units linked to each other in various ways, and are of wide occurrence among marine brown algae ${ }^{21,22}$. Among marine brown algae, 
Ecklonia cava, Ecklonia stolonifera, Ecklonia kurome, Eisenia bicyclis, Ishige okamurae, Sargassum thunbergii, Hizikia fusiformis, Undaria pinnatifida, and Laminaria japonica have been reported for phlorotannins with health beneficial biological activities ${ }^{22}$.

\section{PHLOROTANNINS}

\section{Sources and distribution}

Phlorotannins have only been found to exist within brown algae and may constitute up to $15 \%$ of the dry weight of brown algae ${ }^{23}$. The concentration of phlorotannins is highly variable among different brown seaweeds as well as among different geographical areas. The fucoid species from the Atlantic and the temperate Pacific contain higher concentration of phlorotannins as compared to those obtained from the tropical Pacific ${ }^{24}$. It was found that phlorotannnins have mostly focused on Fucaceae (Ascophyllum nodosum and $\mathrm{Fu}$ cus vesiculosus), Sargassaceae (Sargassum spinuligerum and Carpophyllum angustifolium), and Cystoseiraceae (Cystophora retroflexa and C. torulosa) with concentrations ranging from 20 to $250 \mathrm{mg} / \mathrm{g}$ dry matter ${ }^{25-29}$. They tend to be concentrated within the outer cortical layers, physode, and the mitotic meristematic and meiotic sporogenous tissues ${ }^{30}$. In addition, Laminariaceous brown algae, such as Eisenia bicyclis, Ecklonia cava, Ecklonia kurome were also found to contain a significant amount of phlorotannins ${ }^{31,32}$.

\section{Structural diversity and classification}

Phlorotannins are formed by the polymerization of phloroglucinol (1,3,5-trihydroxybenzene) monomer units. They are highly hydrophilic components with a wide range of molecular sizes ranging between $126 \mathrm{Da}$ and $650 \mathrm{kDa}$. The monomeric units are linked through aryl-aryl bonds and diaryl ether bonds forming different subgroups of phlorotannins ${ }^{33}$. Phlorotannins can be grouped according to the criteria of interphloroglucinol linkages into three primary types including fucols, phlorethols, and fucophlorethols ${ }^{34}$. Fucols is formed by only phenyl linkages, while phlorethols is formed by only arylether bonds and fucophlorethols is formed by both arylether and phenyl linkages ${ }^{35}$. The structural diversity of phlorotannins increases by adding the number of phloroglucinol units. Each of the primary groups can be grouped into linear or branched phlorotannins. In fucols, the interphloroglucinol links at meta-relative position construct of the linear phlorotannin such as tetrafucol-A and the branched phlorotannin such as tetrafucol-B, which were isolated from Fucus vesiculo$s u s^{36,37}$. Moreover, longer oligomers of phlorotannin such as pentafucols and heptafucols were purified from Scytothamnus australii ${ }^{33}$ and Analipus japoni- 
$\mathrm{Cas}^{3^{8}}$. The linear phlorethols such as triphlorethol $\mathrm{C}$ and tetraphlorethols $\mathrm{A}$ and B were isolated from Laminaria ochroleuc ${ }^{39}$. The branched phlorethols include tetraphlorethol C from Ecklonia maxima ${ }^{40}$, pentaphlorethol B and hexaphlorethol A from Cystophora retroflexa ${ }^{27}$. Furthermore, an additional hydroxyl group on the terminal monomer unit forms other structural motifs of phlorethols such as bifuhalol, trifuhalol A, and trifuhalol $\mathrm{B}^{41,42}$. The isofuhalols such as isotrifuhalol has an extension unit that bind between meta-oriented phloroglucinol units and it bears the additional hydroxyl group ${ }^{43}$. Some fuhalols with more than one additional hydroxyl group have been called hydroxyfuhalols, such as hydroxytrifuhalol $\mathrm{B}^{44}$. In addition, another subgroup of phlorethols, the eckols, includes a 1,4-dibenzodioxin system, such as the trimers eckol and dioxinodehydroeckol ${ }^{40}$, the tetramers 2-phloroeckol and 7-phloroeckol ${ }^{45-47}$. In fucophlorethols, the combinations of $\mathrm{C}-\mathrm{C}$ and $\mathrm{C}-\mathrm{O}-\mathrm{C}$ linkages allow the formation of various compounds in linear, branched and heterocyclic fashions. The linear fucophlorethols is fucodiphlorethol- $\mathrm{B}^{48}$, meanwhile the branched fucophlorethols is bisfucotriphlorethol $\mathrm{A}^{25}$, and heterocyclic fucophlorethols is phlorofucofuroeckol A ${ }^{49}$.

\section{Biosynthesis of phlorotannins}

Phlorotannins are biosynthesized via the acetate-malonate pathway, also known as the polyketide pathway, in a process which may involve a polyketide synthase-type enzyme complex ${ }^{50}$. However, the exact biosynthetic pathway for phlorotannins is unknown up to now. Therefore, methodologies that monitor phlorotannin synthesis at the genetic or enzymatic levels could be useful to reveal some of the uncertainties regarding phlorotannin biosynthesis ${ }^{51}$. Firstly, two molecules of acetyl co-enzyme A are converted into malonyl coenzyme A through the addition of carbon dioxide. This addition changes the acetyl methyl group into a highly reactive methylene. Secondly, the process of polymerization is assisted to occur with the low required energy. During further synthesis steps, the carbon dioxide, which was added as an activator, is lost. Thirdly, a polyketide chain consisting of an acid moiety is formed, and the co-enzyme is lost. The polyketide chain is transformed by intermolecular ring closure and elimination of water to produce hexacyclic ring systems. Triketide, the cyclization product, is not stable and thus undergoes transformation into the thermodynamically more stable aromatic form, phloroglucinol, consisting of three phenolic hydroxyl groups ${ }^{52}$. The polymerization of phloroglucinol in different ways results in formation of various phlorotannins. 


\section{Physiological properties}

Phlorotannins are found in physodes, which contribute to the development of the cell wall of brown algae ${ }^{53}$. It has suggested that phlorotannins are likely to be integral structural components of brown-algal cell walls ${ }^{54}$. They are bound to the cell wall during maturation of the plant ${ }^{55}$. Phenolic compounds are bound with four major types of bonds including hydrophobic, hydrogen, ionic, and covalent bond to increase the strength ${ }^{56}$. The cell wall (alginic acid) and phlorotannins are linked via covalent bonds including the ester bond and the hemiacetal bond, thus requiring strong conditions to degrade. Moreover, phlorotannins have a putative role in brown algal reproduction due to exposing on the surface of the recently fertilized zygotes where they may prevent multiple fertilizations by inhibiting spermatozoid movement ${ }^{33}$.

A characteristic of phlorotannins is their plasticity to a variety of environmental factors including nutrient environment ${ }^{57}$, light ${ }^{8}{ }^{8}$, depth ${ }^{59}$, salinity ${ }^{60}$, grazing ${ }^{61}$ or other mechanical wounding ${ }^{62}$. Such plasticity may represent inducible defense against herbivory ${ }^{23}$. Suggestions for other adaptive roles for phlorotannins include protection against ultraviolet radiation ${ }^{63}$ or function as anti-fouling substances $^{64}$. The suggested defensive role of phlorotannins is due to deterring feeding by herbivores ${ }^{65}$ and decreasing their assimilation efficiency by binding with proteins in the gut ${ }^{66,67}$.

\section{PHARMACEUTICAL PROPERTIES OF PHLOROTANNINS}

\section{Antioxidant and UV-protective activities}

The oxidants such as superoxide anion radicals, hydroxyl radical species, and hydrogen peroxide are often generated by biological oxidation reactions of exogenous factors ${ }^{68}$. It is well-known that oxidants are involved in signal transduction and gene activation and can contribute to host cell and organ dama$\mathrm{ge}^{69}$. Therefore, scavenging of oxidant is considered to be important to control various diseases. Interestingly, phlorotannins from marine brown algae have been evidenced to be effective to scavenge oxidants in non-cellular and cellular systems. According to Ahn and colleagues, the antioxidant activities of three phlorotannins including phloroglucinol, eckol and dieckol purified from Ecklonia cava collected in Jeju Island have been investigated ${ }^{70}$. It reported that all the phlorotannins have the potential DPPH, alkyl, hydroxyl and superoxide radical scavenging activities. Eckol exhibit the most strong antioxidant activity via scavenging $93 \%$ of DPPH. Moreover, these phlorotannins were effective to protect DNA against $\mathrm{H}_{2} \mathrm{O}_{2}$-induced damage. In the same trend, Kang and colleagues have also investigated the cytoprotective effect of eckol from 
E. cava against oxidative stress induced cell damage in Chinese hamster lung fibroblast (V79-4) cells ${ }^{71}$. Eckol was effective to reduce $\mathrm{H}_{2} \mathrm{O}_{2}$-induced cell death in V79-4 cells, inhibit radiation-induced cell damage, and scavenge intracellular ROS production. Moreover, eckol was able to increase the activity of catalase and its protein expression via increasing phosphorylation of extracellular signal-regulated kinase and activity of nuclear factor $\mathrm{\kappa B}$. In another study of Kang and colleagues, triphlorethol-A from E. cava was found to reduce intracellular hydrogen peroxide generated by gamma-ray radiation, thus protecting against radiation-induced membrane lipid peroxidation, cellular DNA damage, and cell death ${ }^{72}$. Furthermore, triphlorethol-A augments cellular antioxidant defense capacity through induction of HO-1 expression via ERKNrf2-ARE signaling pathway, thereby protecting cells from oxidative stres ${ }^{73}$. Notably, Li and colleagues have isolated several phlorotannins from E. cava such as phloroglucinol, eckol, fucodiphloroethol G, phlorofucofuroeckol A, dieckol, and 6,6'-bieckol. All phlorotannins were found to possess antioxidant properties via scavenging free radicals, protecting membrane protein from oxidant-induced damage, enhancing cellular glutathione level in RAW264.7 cell line ${ }^{74}$. Likewise, several phlorotannins including phloroglucinol, eckol, dieckol, eckstolonol and triphloroethol A from E. cava were investigated for their activity against AAPH-induced oxidative stress toxicity in zebrafish embryos ${ }^{75}$. All phlorotannins were able to scavenge intracellular ROS, prevent lipid peroxidation and reduce AAPH-induced cell death in zebrafish embryos. In an in vivo study, the role of eckol from $E$. cava as a radioprotective agent against the gamma ray-induced damage has been investigated by Park and colleages ${ }^{76}$. It has been determined that eckol significantly decreased the mortality of lethally irradiated mice via improving the hematopoietic recovery, repairing the damaged DNA in immune cells and enhancing their proliferation. Therefore, eckol is considered as a potential candidate for adjuvant therapy of radiationexposed cancer patients. Recently, the antioxidant properties of phlorotannins from brown seaweed Cystoseira trinodis and Carpophyllum flexuosum was investigated ${ }^{77,78}$. It indicated that the antioxidant activities of these seaweed were due to phlorotanins content and structure.

UV radiation has a strong oxidative component, and photo-oxidative stress has been directly linked to skin photo-damage and associated with abnormal cutaneous reactions such as epidermal hyperplasia, accelerated breakdown of collagen, and inflammatory responses. Herein, dieckol from E. cava has been found to be able to inhibit melanogenesis and protect against photo-oxidative stress induced by UV-B radiation ${ }^{79}$. The inhibitory activity on melanogenesis was evidenced via suppression of tyrosinase and melanin synthesis. Meanwhi- 
le, protective activity was observed via scavenging intracellular ROS, preventing DNA damage, and increasing cell viability. Additionally, Fucofuroeckol-A from E. stolonifera was also found as protective agent against UVB-induced allergic reaction in $\mathrm{RBL}-2 \mathrm{H}_{3}$ mast cells ${ }^{80}$. It was revealed that F-A significantly suppress mast cell degranulation via decreasing histamine release as well as intracellular $\mathrm{Ca}^{2+}$ elevation induce by UVB. Notably, the protective activity of F-A against mast cell degranulation was found due to scavenging ROS production. According to Klervi and colleagues, the ethyl acetate fraction of brown macroalga (Halidrys siliquosa) appeared to be a broad-spectrum UV-A absorber $^{81}$. This activity was found due to the present of four phenolic compounds including trifuhalols, tetrafuhalols, diphlorethols, and triphlorethols. These results indicated that phlorotannins from brown algae have potential protective effects against UV radiation, which might be applied in cosmeceutical industries.

\section{Antimicrobial activity}

Infectious diseases caused by bacteria and fungi are still a major threat to public health, despite the tremendous progress in human medicine. Increasing resistance of clinically important bacteria to existing antibiotics is a major problem throughout the world ${ }^{82}$. The discovery of novel antimicrobial compounds for clinical application is necessary to check the global crisis of antibiotic resistance. In this regard, phlorotannins from brown algae have been found to possess antimicrobial effect against food-borne pathogenic bacteria, antibiotic resistance bacteria, and pathogenic fungi. According to Nagayama and colleagues, the oral administration of phlorotannins from E. kurome on mice results in effective inhibition against methicillin-resistant Staphylococcus aureus (MRSA). The minimum bactericidal concentrations (MBCs) of eckol, phlorofucofuroeckol A, dieckol, and 8,8'-bieckol against Campylobacter jejuni were 0.08 , 0.08, 0.03, and $0.03 \mu \mathrm{mol} / \mathrm{ml}$, respectively. At twice the MBCs, all Vibrio parahaemolyticus were killed within $0.5^{-2} \mathrm{~h}$, while catechins showed little bactericidal activity within $4 \mathrm{~h}^{83}$. Furthermore, Lee and collaborators have determined that dieckol from E. stolonifera exhibited antibacterial activity against methicillin-susceptible S. aureus (MSSA) and MRSA in a range of minimum inhibitory concentrations (MICs) of 32 to $64 \mu \mathrm{g} / \mathrm{ml}^{84}$. The MICs of ampicillin against two standard strains of MRSA were dramatically reduced from 512 to $0.5 \mu \mathrm{g} / \mathrm{ml}$ in combination with 1/4 MIC of dieckol (16 $\mu \mathrm{g} /$ $\mathrm{ml}$ ). Likewise, Phlorofucofuroeckol-A from E. bicyclis were also showed antiMRSA activity with MIC of $32 \mu \mathrm{g} / \mathrm{ml}$ and synergistic action against MRSA in combination with $\beta$-lactam antibiotics ampicillin, penicillin, and oxacillin ${ }^{85}$. 
Thereby, phlorotannins- $\beta$-lactam antibiotics combinations exert a synergistic effect against MRSA, indicating the promising treatment of MRSA infections. In addition, it has shown that phlorofucofuroeckol-A from E. cava and E. bicyclis exhibited effective inhibition against Propionibacterium acnes, which may be useful as natural additives in anti-acne cosmetic products ${ }^{86,87}$. Although the relationship between the structure and anti-bacterial activity of the phlorotannins is limited, their inhibitory activity may be suggested to depend on the degree of polymerization of phlorotannin derivatives.

Besides, the purified phlorotannins extracts from three brown seaweeds including Cystoseira nodicaulis, C. usneoides, and Fucus spiralis displayed their antifungal activity against human pathogenic yeast and filamentous fungi ${ }^{88}$. It was revealed that $C$. albicans ATCC 10231 was the most susceptible among yeast, while Epidermophyton floccosum and Trichophyton rubrum were the most susceptible among dermatophytes. It was found that $C$. nodicaulis and $C$. usneoides seem to act by affecting the ergosterol composition of the cell membrane of yeast and dermatophyte, respectively. Meanwhile, F. spiralis influenced the dermatophyte cell wall composition by reducing the levels of chitin. Moreover, phlorotannins from $F$. spiralis inhibited the dimorphic transition of Candida albicans, leading to the formation of pseudohyphae with diminished capacity to adhere to epithelial cells. On the other hand, the potential fungicidal activity of dieckol from E. cava was also found due to inhibition of Trichophyton rubrum associated with dermatophytic nail infections in human ${ }^{89}$.

\section{Anti-HIV activity}

Human immunodeficiency virus type-1 (HIV-1) is the cause of acquired immune deficiency syndrome (AIDS) which has been a major human viral disease with about 33.2 million people infected worldwide up to now ${ }^{90}$, 91. Antiviral agents that interfere with HIV at different stages of viral replication have been developed ${ }^{92,93}$. However, failure in anti-AIDS treatment is observed by the emergence of resistant virus, cross-resistance to drugs and cell toxicity ${ }^{94,95}$. Therefore, the search for potential candidates containing higher inhibitory activity against various HIV strains is increasing in pharmaceutical industry. Accordingly, phlorotannins from brown algae have been revealed to possess antiHIV activity. For the first time, Ahn et al. (2004) reported that 8,8'-bieckol and 8,4"'-dieckol from E. cava exhibited an inhibitory effect on HIV-1 reverse transcriptase and protease ${ }^{96}$. The inhibition against reverse transcriptase of $8,8^{\prime}$-bieckol with a biaryl linkage $\left(\mathrm{IC}_{50}, 0.5 \mu \mathrm{M}\right)$ is ten-fold higher than that of $8,4^{\prime \prime \prime}$-dieckol with a diphenyl ether linkage $\left(\mathrm{IC}_{50}, 5.3 \mu \mathrm{M}\right)$, although these two phlorotannins are dimmers of eckol. They have suggested that the steric hind- 
rance of the hydroxyl and aryl groups near the biaryl linkage of 8,8'-bieckol caused to the potent inhibitory activity. Moreover, 8,8'-bieckol selectively inhibits reverse transcriptase over protease and inhibitory effect is comparable to the positive control nevirapine $\left(\mathrm{IC}_{50}, 0.28 \mu \mathrm{M}\right.$ ). Moreover, kinetic study showed that 8,8'-bieckol inhibited the RNA-dependent DNA synthesis activity of HIV-1 reverse transcriptase noncompetitively against dUTP/dTTP with a Ki value of $0.78 \mu \mathrm{M}$. Meanwhile, this compound also exhibited an uncompetitive inhibition ( $\mathrm{Ki}, 0.23 \mu \mathrm{M})$ with respect to a homopolymeric template/primer, $(\mathrm{rA})_{\mathrm{n}}(\mathrm{dT})_{15}$. A possible suggestion for this phenomenon is that 8,8'-bieckol binds to HIV-1 reverse transcriptase only after the template/primer initially binds to the enzyme. Furthermore, Ahn et al. (2006) has shown that diphlorethohydroxycarmalol from I. okamurae also has inhibitory effect on HIV-197. This compound exhibited inhibitory effects on HIV-1 reverse transcriptase and integrase with $\mathrm{IC}_{50}$ values of $9.1 \mu \mathrm{M}$ and $25.2 \mu \mathrm{M}$, respectively. However, diphlorethohydroxycarmalol did not show an inhibitory activity against HIV-1 protease. In the same trend, 6,6'-bieckol from E. cava has been found as a potent wild inhibition against HIV-1 induced syncytia formation, lytic effects, and viral p24 antigen production ${ }^{98}$. This phlorotannin has selectively inhibited the activity of HIV-1 reverse transcriptase enzyme with an $\mathrm{IC}_{50}$ of $1.07 \mu \mathrm{M}$ without any cytotoxicity. Recently, Kwon and colleagues have found that phlorotannins including eckol, 7-phloroeckol, phlorofucofuroeckol, and dieckol possessed antiviral activities with $\mathrm{IC}_{50}$ range of $10.8-22.5 \mu \mathrm{M}$ against porcine epidemic diarrhea virus ${ }^{99}$. These phlorotannins were completely blocked binding of viral spike protein to sialic acids at less than $36.6 \mu \mathrm{M}$ by hemagglutination inhibition. Notably, phlorofucofuroeckol and dieckol inhibited viral replication with $\mathrm{IC}_{50}$ values of 12.2 and $14.6 \mu \mathrm{M}$ in the post-treatment assay, respectively. Interestingly, phlorofucofuroeckol and dieckol inhibited both viral entry by hemagglutination inhibition and viral replication by inhibition of viral RNA and viral protein synthesis, but not viral protease.

\section{Anti-allergic activity}

Allergic disease including allergic rhinitis, asthma, and atopic eczema are among the commonest causes of chronic ill-health. It is caused by an exaggerated reaction of the immune system to harmless environmental substances, such as animal dander, house dust mites, foods, pollen, insects, and chemical agents $^{100,101}$. Allergic reaction is characterized by the excessive activation of mast cells and basophils by immunoglobulin E (IgE) from B cells, resulting in the release of preformed inflammatory mediators from secretory granules such as histamine and $\beta$-hexosaminidase, the generation and secretion of the newly 
synthesized substances such as leukotrienes, prostaglandins, and cytokines ${ }^{102}$. These mediators cause allergic inflammatory responses due to airway constriction, mucous production, and recruitment of inflammatory cells. So far, a large number of anti-allergic agents from natural products have been identified based on the specific assay system or screening approaches. Recently, phlorotannins from brown algae have been determined as potential natural inhibitors of allergic reactions due to suppression of allergic degranulation, inhibition of hyaluronidase enzyme, and blockade of FceRI activities. Several bioactive phloroglucinol derivatives including fucodiphloroethol G, eckol, dieckol, 6,6'-bieckol, phlorofucofuroeckol A, and 1-(3' ,5'-dihydroxyphenoxy)7-(2" ", 4" ,6-trihydroxyphenoxy)-2,4,9-trihydroxydibenzo-1,4-dioxin were isolated from E. cava and evidenced against A23187 or FceRI-mediated histamine release from KU812 and RBL-2H3 cells ${ }^{103},{ }^{32}$. Especially, dieckol, 6,6' $6^{\prime}$-bieckol, and fucodiphloroethol $\mathrm{G}$ exhibited a significantly inhibitory activity with $\mathrm{IC}_{50}$ range of $27.80-55.12 \mu \mathrm{M}$. The inhibitory mechanism of these compounds was determined to be due to blocking the binding activity between IgE and FceRI. Similarly, Shim et al. (2009) have proved that phlorotannins of dioxinodehydroeckol and phlorofucofuroeckol A from E. stolonifera induced a suppression of the cell surface FceRI expression, and total cellular protein and mRNA levels of the FceRI $\alpha$ chain in KU812 cells ${ }^{104}$. Further, both of these compounds exerted inhibitory effects against intracellular calcium elevation and histamine release from anti-FceRI $\alpha$ chain antibody (CRA-1)-stimulated cells. In another study, phlorotannin PFF-B obtained from E. arborea exposed strong inhibitory activity against histamine and $\beta$-hexosaminidase release with $\mathrm{IC}_{50}$ value of $7.8 \mu \mathrm{M}^{105}$, 106. Obviously, PFF-B had a 2.8-6.0 times greater inhibitory activity than those of epigallocatechin gallate $\left(\mathrm{IC}_{50}=22.0 \mu \mathrm{M}\right)$ or Tranilast $\left(\mathrm{IC}_{50}=46.6 \mu \mathrm{M}\right)$, a clinically used anti-allergic drug ${ }^{107}$. Thus, these bioactive phloroglucinol derivatives were suggested as a promising candidate for the design of novel inhibitor of FceRI-mediated allergic reaction. For the first time, the anti-allergenicity of phlorotannin from four edible seaweed species of Fucus genus was evaluated by Barbosa and colleagues ${ }^{108}$. It was found that Fucus was able to inhibit mast cell degranulation via decreasing histamine and beta-hexosaminidase release from the activated RBL-2H3 cells, contributing to the valorisation of Fucus spp. both as food and for nutraceutical applications.

Hyaluronidase depolymerizes the polysaccharide hyaluronic acid in the extracellular matrix of connective tissue, which is found both in organs and in body fluids. It is mainly known to be involved in the permeability of the vascular system $^{109}$ and allergic reaction ${ }^{110,111}$. Interestingly, various phlorotannins such 
as phlorofucofuroeckol A, dieckol, and 8,8'-bieckol from E. bicyclis are able to inhibit hyaluronidase enzyme with $\mathrm{IC}_{50}$ values of 140,120 , and $40 \mu \mathrm{M}$, respectively ${ }^{112}$. The effect of these phlorotannins against hyaluronidase enzyme is stronger than well-known inhibitors such as catechins $\left(\mathrm{IC}_{50}=620 \mu \mathrm{M}\right)$ and sodium cromoglycate $\left(\mathrm{IC}_{50}=270 \mu \mathrm{M}\right)$. Notably, 8,8' -bieckol, the strongest hyaluronidase inhibitor among the tested phlorotannins, acted as a competitive inhibitor with an inhibition constant of $35 \mu \mathrm{M}$. Likewise, several phlorotannins of 6,6'-bieckol, 6,8' -bieckol, 8,8' -bieckol, PFF-A, and PFF-B from $E$. arborea were also confirmed as strong inhibitors of hyaluronidase ${ }^{113,114}$.

\section{Anti-inflammatory activity}

Inflammation is a critically important aspect of host responses to various stimuli including physical damage, ultra violet irradiation, microbial invasion, and immune reactions $\mathbf{s}^{115}$, 116. It is associated with a large range of mediators that initiate the inflammatory response, recruit and activate other cells to the site of inflammation ${ }^{117}$. However, excessive or prolonged inflammation can prove harmful, contributing to the pathogenesis of a variety of diseases, including chronic asthma, rheumatoid arthritis, multiple sclerosis, inflammatory bowel disease, psoriasis, and cancer ${ }^{116}$. Currently, several classes of drugs such as corticosteroids, nonsteroidal anti-inflammatory drugs, and aspirin are used to treat the inflammatory disorders. All these therapeutics help to alleviate the symptoms but, especially after long-term and high-dose medication, they can have quite substantial side-effects. Therefore, there is still a vital need for the development of new anti-inflammatory drugs with satisfactory tolerability for long-term use. Herein, phlorotannins have been evidenced as potential agents for down-regulation of inflammatory responses. Phlorotannin-rich extracts of $E$. cava showed significant suppression of $\mathrm{PGE}_{2}$ generation in LPS-treated RAW 246.7 cells, and significant inhibition of human recombinant interleukin$1 \alpha$-induced proteoglycan degradation ${ }^{118}$. Moreover, the phlorotannin-rich the fermented E. cava processing by-product extract was reported to inhibit NO and $\mathrm{PGE}_{2}$ production, suppress the inducible nitric oxide synthase (iNOS) and cyclooxygenase-2 (COX-2) expressions, and attenuate interleukin-1 $\beta$ and interleukin-6 production in lipopolysaccharide stimulated RAW 264.7 cells $^{119}$. Recently, phlorotannin 6,6'-bieckol from E. cava was found to inhibit NO and $\mathrm{PGE}_{2}$ production by suppressing the expression of iNOS and COX-2 at the mRNA and protein levels in LPS-stimulated primary macrophages and RAW 264.7 macrophage cells ${ }^{120}$. Moreover, 6,6'-bieckol down-regulated the production and mRNA expression of the inflammatory cytokines TNF- $\alpha$ and IL-6. The pretreatment of 6,6'-bieckol decreased LPS-induced transactivation 
of nuclear factor-kappa B (NF- $\kappa \mathrm{B})$ and nuclear translocation of p5o and p65 subunits of NF- $\kappa B$, thus inhibiting LPS-induced NF- $\kappa B$ binding to the TNF- $\alpha$ and IL-6 promoters. On the other hand, Kim and collaborators have evidenced that phlorofucofuroeckol A from E. stolonifera attenuated the productions and expression of $\mathrm{NO}, \mathrm{PGE}_{2}$, and pro-inflammatory cytokines such as IL-1 $\beta$, IL6 , and TNF- $\alpha$ in LPS-stimulated microglia. Profoundly, phlorofucofuroeckol A treatment showed inactivation of c-Jun NH2-terminal kinases (JNKs), p38 mitogen-activated protein kinase (MAPK), Akt, and NF- $\mathrm{B}^{121}$. Likewise, Kim et al. (2009) have shown the inhibitory activity of this phlorofucofuroeckol A on $\mathrm{NO}$ and $\mathrm{PGE}_{2}$ production and iNOS and COX-2 expression in RAW 264.7 murine macrophage cells ${ }^{122}$. Besides, phlorotanins from $E$. arborea also exhibited inhibitory effect on NO production in LPS-stimulated RAW 264.7 cells $^{123}$ and mouse ear edema induced by arachidonic acid, 12-O-tetradecanoyl phorbol13-acetate, and oxazolone ${ }^{124}$. Notably, 8,8' -bieckol from E. bicyclis showed the pronouncedly inhibitory effects on soybean lipoxygenases and 5 -lipoxygenases with $\mathrm{IC}_{50}$ values of 38 and $24 \mu \mathrm{M}$, respectively. Meanwhile, dieckol presented a significant inhibition of COX-1 with inhibition rate of $74.7 \%{ }^{125}$. Similarly, 6,6'-bieckol, 6,8'-bieckol, 8,8'-bieckol, PFF-A, and PFF-B from E. arborea were also confirmed as strong inhibitors of phospholipase $\mathrm{A}_{2}$, cyclooxygenase, and lipoxygenases, which correlated to suppression in synthesis and release of leukotoriene and prostaglandin from RBL cells ${ }^{114}$. Recently, phlorotannin-rich extract of the edible brown alga $E$. cava against hyper-inflammatory response in LPS-induced septic shock mouse model was also investigated ${ }^{126}$. Dieckol, a major compound in the extract, reduced mortality, tissue toxicity, and serum levels of the inflammatory factors in septic mice and suppressed the septic shock through negative regulation of pro-inflammatory factors via the $\mathrm{NIK} / \mathrm{TAK} 1 / \mathrm{IKK} / \mathrm{I} \kappa \mathrm{B} / \mathrm{NF} \kappa \mathrm{B}$ and Nrf2/HO-1 pathways. In addition, Barbosa and colleagues have demonstrates the marked potential of Fucus sp. and their phlorotannin-purified extracts to act upon different mediators important in the pathophysiology of inflammatory-related conditions ${ }^{127}$. The anti-inflammatory potential of the purified phlorotannin extracts in both cell and cell-free systems was observed. Therefore, the phlorotannin extracts from Fucales arise as potentially beneficial in inflammation-related conditions, effectively acting upon enzymatic and non-enzymatic inflammatory target.

\section{Anti-cancer activity}

Cancer can be defined as a disease in which a group of abnormal cells grow uncontrollably by disregarding the normal rules of the cell division ${ }^{128}$. Cancers may be caused in one of three ways, namely incorrect diet, genetic predisposition, and via the environment. At least $35 \%$ of all cancers worldwide are caused 
by an incorrect diet. Meanwhile, genetic predisposition caused about 20\% of cancer cases, thus leaving the majority of cancers being associated with a host of environmental carcinogens ${ }^{129}$. It is necessary to avoid exposure to cancercausing biological, chemical, and physical agents, and consume chemo-preventive agents to reduce cancer risk. A promising approach is associated with natural products that are available as anti-cancer agents against commonly occurring cancers occurring worldwide ${ }^{130,131}$. Recently, phlorotannins have been reported as novel promising anti-cancer agent for breast cancer. Kong et al. (2009) has indicated that dioxinodehydroeckol from E. Cava exerted anti-proliferative activity against human breast cancer cells via induction of apoptosis ${ }^{132}$. Dioxinodehydroeckol treatment caused the increase in caspase (-3 and -9) activity, DNA repair enzyme poly-(ADP-ribose) polymerase (PARP) cleaved, and pro-apoptotic gene (Bax, p53, and p21) and the decrease in anti-apoptotic gene Bcl-2 and NF- $\mathrm{kB}$ activation. Moreover, phlorotannins-rich extracts from Palmaria, Ascophyllum and Alaria also inhibited the proliferation of colon cancer cells ${ }^{133}$. On the other hand, the anti-cancer activity of S. muticum polyphenol-rich seaweed was shown via inhibiting breast cancer cell proliferation with $\mathrm{IC}_{50}$ of $22 \mu \mathrm{g} / \mathrm{ml}$ and inducing apoptosis from $13 \%$ to $67 \%$ by accumulation of cells at sub-G1 phase ${ }^{134}$. Parys et al. (2010) reported that trifucodiphlorethol A, trifucotriphlorethol A and fucotriphlorethol A from Fucus vesiculosus were the potential chemo-preventive agents due to their capacity to inhibit the activity of aromatase related to carcinogenesis from breast cancers $^{135}$. For the first time, Kim and colleages have determined the inhibitory effects of phlorotannins isolated from E. cava on MMP activities in cultured human cell lines without any cytotoxic effect ${ }^{136}$. Recently, the anti-proliferative effect of various brown algae including Cystoseira crinita, Cystoseira stricta, and Sargassum vulgare on the human epithelial cell line Caco-2 was evidenced via arresting in $\mathrm{G}$ phases along with an increment in sub-diploidal cell population $^{137}$. The anti-proliferative effect of these algae was correlated with their polyphenol and flavonoid contents. Moreover, the phlorotannins recovered from hydrothermal treatment of Sargassum muticum were showed the anti-proliferative properties against lung adenocarcinoma A549 cells and colon carcinoma HCT-116 cells ${ }^{138}$. These results imply that seaweeds which are rich in phlorotannins may be used in anti-cancer drug research programs.

\section{Anti-diabetic activity}

Diabetes mellitus is a chronic metabolic disorder involved in hyperglycaemia, resulting from the deficiency in the production of insulin by the pancreas. Up to now, numerous therapeutics have been proposed to control hyperglycaemia in diabetic patients. Especially, $\alpha$-amylase and $\alpha$-glucosidase are enzymes related 
to hyperglycaemia due to the starch hydrolysis and release of the glucose monomers for subsequent absorption by the small intestine. Therefore, the inhibition of these enzymes reduces the availability of free glucose monomers and consequently decreases blood glucose levels ${ }^{139}$. Rengasamy et al. (2013) has isolated three phlorotannins including dibenzo $(1,4)$ dioxine-2,4,7,9-tetraol and eckol from E. maxima and evaluated their alpha-glucosidase inhibitory activities ${ }^{140}$. The inhibitory activities of dibenzo $(1,4)$ dioxine-2,4,7,9-tetraol and eckol on enzyme alpha-glucosidase were 33.7 and $11.2 \mu \mathrm{M}$, respectively. A phenolic-rich extract from Ascophyllum was effective to inhibit a-amylase and $\alpha$-glucosidase with $\mathrm{IC}_{50}$ of $0.1 \mu \mathrm{g} / \mathrm{ml} \mathrm{GAE}$ and $20 \mu \mathrm{g} / \mathrm{ml} \mathrm{GAE}^{133}$. The presence of fucophloroethol structures with degrees of polymerization from 3 to 18 monomer units in Fucus distichus is responsible for its inhibition on a-glucosidase and $\alpha$-amylase, with $\mathrm{IC}_{50}$ values of 0.89 and $13.9 \mu \mathrm{g} / \mathrm{ml}^{141}$. Moreover, dieckol and eckol from Eisenia bicyclis exhibited the inhibitory activity on a-amylase up to 97.5 and $87.5 \%$ at $1 \mathrm{mM}^{142}$. Meanwhile, $\alpha$-glucosidase was inhibited by phlorofucofuroeckol-A, dieckol, and 7-phloroeckol from E. stolonifera and eckol and dioxinodehydroeckol from E. bicyclis with $\mathrm{IC}_{50}$ of 1.37, 1.61, 6.13, 22.78 , and $34.6 \mu \mathrm{M}$, respectively ${ }^{143}$. The ingestion of methanolic extract of $E$. stolonifera suppressed the increase in plasma glucose and lipid peroxidation levels in unfasted KK-A(y) mice ${ }^{144}$. Furthermore, various phlorotannins from E. stolonifera exhibited the inhibitory activities on aldose reductase, which are highly implicated in hyperglycemia and oxidative stress. The $\mathrm{IC}_{50}$ values of phloroglucinol derivatives are $21.95-125.45 \mu \mathrm{M}^{145}$. Besides, dieckol from $E$. cava has evidenced prominent inhibitory effect against alpha-glucosidase and alpha-amylase with $\mathrm{IC}_{50}$ values of 0.24 and $0.66 \mathrm{mM}$, respectively. The increase of postprandial blood glucose levels were significantly suppressed in the dieckol administered group in the streptozotocin-induced diabetic mice ${ }^{146}$. Recently, three phlorotannins, eckol, dieckol and phlorofucofuroeckol-A from $E$. bicyclis were revealed for their anti-diabetic activity of alloxan-induced type1 and insulin-induced type 2 in the zebrafish model ${ }^{147}$. Notably, the inhibition of the catalytic reaction of $\alpha$-glucosidase by minor phlorotannin derivatives from E. cava were demonstrated with $\mathrm{IC}_{50}$ values ranging from $2.3 \pm 0.1$ to $59.8 \pm$ $0.8 \mu \mathrm{M}$. Compounds $2-5$ inhibited the catalytic reaction of $\alpha$-glucosidase in non-competitive and competitive manners ${ }^{148}$.

\section{Anti-obesity}

Obesity is a major obstacle in human health and life quality, resulting in many chronic diseases. It is due to a chronic imbalance between energy intake and energy expenditure, leading to the increased fat storage ${ }^{149}$. Interestingly, a series of anti-obesity components derived from marine origin have been found, 
especially phlorotannins. Herein, three phlorotannins from E. stolonifera including phloroglucinol, eckol, and phlorofucofuroeckol A significantly inhibited lipid accumulation in 3T3-L1 cells via reducing the expression of adipocyte marker genes such as proliferator activated receptor $\gamma$ and CCAAT/enhancerbinding protein $\alpha^{150}$. Meanwhile, phlorotannin dieckol from $E$. cava exhibited great potential adipogenesis inhibition and down-regulated the expression of peroxisome proliferator-activated receptor- $\gamma$, CCAAT/enhancer-binding proteins, sterol regulatory element-binding protein 1 (SREBP1) and fatty acid binding protein $4^{151}$. Moreover, diphlorethohydroxycarmalol (DPHC) from Ishige okamurae was showed to inhibit population growth and induce apoptosis in 3T3-L1 preadipocytes ${ }^{152}$. The peptidyl prolyl cis/trans isomerase Pin1 enhances the uptake of triglycerides and the differentiation of fibroblasts into adipose cells in response to insulin stimulation. However, phlorotannin called 974-B from E. kurome was showed to inhibit the differentiation of mouse embryonic fibroblasts and $3 \mathrm{~T}_{3}-\mathrm{L} 1$ cells into adipose cells without inducing cytotoxicity, suggesting a lead drug candidate for obesity-related disorders ${ }^{153}$.

\section{Other biological activities}

According to Ahn et al. (2010), phloroglucinol from E. cava possesses the activation activity on immune response. The phloroglucinol elicited the proliferation of lymphocytes without cytotoxicity and enhanced IL-2 production by activating the nuclear factor-kappaB $(\mathrm{NF}-\mathrm{\kappa B})$ signaling pathway ${ }^{154}$.

Inhibition of angiotensin I-converting enzyme (ACE) activity is the most common mechanism underlying the lowering of blood pressure. Dieckol from $E$. cava was found as potent $\mathrm{ACE}$ inhibitor with $\mathrm{IC}_{50}$ value of $1.47 \mathrm{mM}$. It is a non-competitive inhibitor against ACE according to Lineweaver-Burk plots ${ }^{155}$. Meanwhile, eckol, phlorofucofuroeckol A, and dieckol from E. stolonifera were also determined to manifest the marked inhibitory activity against ACE, with $\mathrm{IC}_{50}$ values of $70.82,12.74$, and $34.25 \mu \mathrm{M}$, respectively ${ }^{156}$.

Neurodegenerative diseases are characterized by progressive dysfunction and death of neurons. Recently, neuroprotective effects of phlorotannins from brown seaweed have been evidenced by various experimental models. Um and colleagues have reported that phlorotannin-rich fraction from Ishige foliacea brown seaweed prevents the scopolamine-induced memory impairment in mice $^{157}$. It reduced acetylcholinesterase activity in the brain and significantly decreased lipid peroxidation levels, but increased glutathione levels and superoxide dismutase activity. Moreover, the expression levels of brain-derived neurotrophic factor, tropomyosin receptor kinase B, the phosphorylated extracellular signal-regulated kinase, and cyclic AMP-response element-binding 
protein were increased by I. foliacea phlorotannin. In addition, the neuroprotective effect of dieckol from $E$. cava on rotenone-induced oxidative stress in a human dopaminergic neuronal cell line $\mathrm{SH}_{-} \mathrm{SY}_{5} \mathrm{Y}$ was also determined by Cha and colleagues ${ }^{158}$. Dieckol reduced the intracellular reactive oxygen species and cytochrome $\mathrm{C}$ release, cell death, and $\alpha$-synuclein aggregation in $\mathrm{SH}_{5} \mathrm{SY}_{5} \mathrm{Y}$ cells. Likewise, it was found that eckmaxol, a phlorotannin from E. maxima, could produce neuroprotective effects in $\mathrm{SH}_{-} \mathrm{SY}_{5} \mathrm{Y}$ cells via directly acting on glycogen synthase kinase $3 \beta^{159}$. Accordingly, phlorotannin from the brown algae could be a potential therapeutic agent for the prevention of neurodegenerative diseases.

\section{RESULTS AND DISCUSSION}

Finding the safe and efficient agents from natural products for prevention and treatment of chronic diseases are always necessary. Herein, phlorotannins from brown algae have been identified with various biological activities and health benefit effects. The extensive discoveries of phlorotannins underlying structure-activity relationship will provide clear evidence on their actions against diseases. Moreover, the further studies due to the bioavailability involving in liberation, absorption, distribution, metabolism, and elimination phases will ensure the bio-efficacy of phlorotannins. Collectively, phlorotannins from brown algae are believed to play an important role in the development of promising pharmaceutical products that can prevent and/or treat various chronic diseases.

\section{ACKNOWLEDGEMENT}

This review is supported by Nguyen Tat Thanh University, Ho Chi Minh city, Vietnam.

\section{CONFLICT OF INTEREST}

There are no conflicts to declare.

\section{REFERENCES}

1. Faulkner, D. J. Marine natural products. Nat Prod Rep. 2002, 19, 1-48.

2. Blunt, J. W.; Copp, B. R.; Munro, M. H.; Northcote, P. T.; Prinsep, M. R. Marine natural products. Nat Prod Rep. 2010, 27, 165-237.

3. Molinski, T. F.; Dalisay, D. S.; Lievens, S. L.; Saludes, J. P. Drug development from marine natural products. Nat Rev Drug Discov. 2009, 8, 69-85.

4. Mayer, A. M.; Glaser, K. B; Cuevas, C.; Jacobs, R. S.; Kem, W.; Little, R. D.; McIntosh, J. M.; Newman, D. J.; Potts, B. C.; Shuster, D. E. The odyssey of marine pharmaceuticals: a current pipeline perspective. Trends Pharmacol Sci. 2010, 31, 255-265. 
5. Mayer, A. M. S.; Glaser, K. B. Marine Pharmacology and the Marine Pharmaceuticals Pipeline. The FASEB J. 2013, 27, 1167.7

6. Ngo, D. H.; Wijesekara, I.; Vo, T. S.; Ta, Q. V.; Kim, S. K. Marine food-derived functional Ingredients as potential antioxidants in the food industry: An overview. Food Res Int. 2011, $44,523-529$.

7. Ngo, D. H.; Ryu, B.; Vo, T. S.; Himaya, S. W.; Wijesekara, I.; Kim, S. K. Free radical scavenging and angiotensin-I converting enzyme inhibitory peptides from Pacific cod (Gadus macrocephalus) skin gelatin. Int J Biol Macromol. 2011, 49, 1110-1116.

8. Ngo, D. H.; Vo, T. S.; Ngo, D. N.; Wijesekara, I.; Kim, S. K. Biological activities and potential health benefits of bioactive peptides derived from marine organisms. Int $J$ Biol Macromol. 2012, 51, 378-383.

9. Ngo, D. H.; Ryu, B.; Kim, S. K. Active peptides from skate (Okamejei kenojei) skin gelatin diminish angiotensin-I converting enzyme activity and intracellular free radical-mediated oxidation. Food Chem. 2014, 143, 246-255.

10. Vo, T. S.; Kim, S. K. Potential Anti-HIV Agents from Marine Resources: An Overview, Mar Drugs. 2010, 8, 2871-2892.

11. Vo, T. S.; Ngo, D. H.; Ta, Q.V.; Kim, S. K. Marine organisms as a therapeutic source against herpes simplex virus infection. Eur J Pharm Sci. 2011, 44, 11-20.

12. Vo, T. S.; Kong, C. S.; Kim, S. K. Inhibitory effects of chitooligosaccharides on degranulation and cytokine generation in rat basophilic leukemia RBL-2H3 cells. Carbohyd Polym. 2011, 84, 649-655.

13. Vo, T. S.; Kim, S. K. Fucoidan as a natural bioactive ingredient for functional foods. $J$ Funct Foods. 2013, 5, 16-27.

14. Vo, T. S.; Kim, S. K. Down-regulation of histamine-induced endothelial cell activation as potential anti-atherosclerotic activity of peptides from Spirulina maxima. Eur J Pharm Sci. 2013, 50, 198-207.

15. Bold, H. C.; Wynne, M. J. In Introduction to the algae structure and reproduction, 2nd ed.; Prentice-Hall Inc: New Jork, 1985.

16. Gamal, A. A. Biological importance of marine algae. Saudi Pharm J. 2010, 18, 1-25.

17. Vo, T. S.; Ngo, D. H.; Kim, S. K. Potential Targets for Anti-Inflammatory and AntiAllergic Activities of Marine Algae: An Overview. Inflamm Allergy Drug Targets. 2012, 11, 90-101.

18. Vo, T. S.; Ngo, D. H.; Kim, S. K. Marine algae as a potential pharmaceutical source for anti-allergic therapeutics. Process biochem. 2012, 47, 386-394.

19. Lincoln, R. A.; Strupinski, S.; Walker, J. M. Bioactive compounds from algae. Life Chem Rep. 1991, 8, 97-183.

20. Gupta, S.; Abu-Ghannam, N. Bioactive potential and possible health effects of edible brown seaweeds. Trends Food Sci Technol. 2011, 22, 315-326.

21. Singh, I. P.; Bharate, S. B. Phloroglucinol compounds of natural origin. Nat Prod Rep. 2006, 23, 558-591.

22. Li, Y. X.; Wijesekaraa, I.; Li, Y.; Kim, S. K. Phlorotannins as bioactive agents from brown 
algae. Process Biochem. 2011, 46, 2219-2224.

23. Targett, N. M.; Arnold, T. M. Predicting the effects of brown algal phlorotannins on marine herbivores in tropical and temperate oceans. J Phycol. 1998, 34, 195-205.

24. Arnold, T. M.; Targett, N. M. To grow and defend: lack of trade-offs for brown algal phlorotannins. Oikos. 2003, 100, 406-408.

25. Glombitza, K. W.; Hauperich, S. Phlorotannins from the brown alga Cystophora torulosa. Phytochemistry. 1997, 46, 735-740.

26. Glombitza, K. W.; Schmidt, A. Trihydroxyphlorethols from the brown alga Carpophyllum angustifolium. Phytochemistry. 1999, 51, 1095-1100.

27. Sailler, B.; Glombitza, K. W. Phlorethol and fucophlorethol from the brown alga Cystophora retroflexa. Phytochemistry. 1999, 50, 869-881.

28. Toth, G. B.; Pavia, H. Water-borne cues induce chemical defense in a marine alga (Ascophyllum nodosum). Prot Natl Acad Sci USA. 2000, 97, 14418-14420.

29. Arnold, T. M.; Targett, N. M.; Tanner, C. E.; Hatch, W. I. Evidence for methyl jasmonateinduced phlorotannin production in Fucus vesiculosus (Phaeophyceae). J Phycol. 2001, 37, 1026-1029.

30. Shoenwaelder, M. E. A. The occurrence and cellular significance of physodes in brown algae. Phycologia. 2002, 41, 125-139.

31. Nakamura, T.; Nagayama, K.; Uchida, K.; Tanaka, R. Antioxidant activity of phlorotannins isolated from the brown alga Eisenia bicyclis. Fisheries Sci. 1996, 62, 923-926.

32. Le, Q. T.; Li, Y.; Qian, Z. J.; Kim, M. M.; Kim, S. K. Inhibitory effects of polyphenols isolated from marine alga Ecklonia cava on histamine release. Process Biochem. 2009, 44, $168-176$.

33. Glombitza, K. W.; Pauli, K. Fucols and phlorethols from the brown alga Scytothamnus australis Hook. et Harv. (Chnoosporaceae). Bot Mar. 2003, 46, 315-320.

34. Isaza Martı́nez, J. H.; Torres Castan eda, H. G. Preparation and Chromatographic Analysis of Phlorotannins. $J$ Chromatogr Sci. 2013, 51, 825-838.

35. Keusgen, M.; Glombitza, K. W. Phlorethols, fuhalols and their derivatives from the brown alga Sargassum spinuligerum. Phytochemistry. 1995, 38, 975-985.

36. Glombitza, K. W.; Rauwald, H. W.; Eckhardt, G. Fucole, Polyhydrox yoligophenyle aus Fucus vesiculosus. Phytochemistry. 1975, 14, 1403-1405.

37. Truus, K.; Vaher, M.; Koel, M.; Mähar, A.; Taure, I. Analysis of bioactive ingredients in the brown alga Fucus vesiculosus by capillary electrophoresis and neutron activation analysis. Anal Bioanal Chem. 2004, 379, 849-852.

38. Glombitza, K. W.; Zieprath, G. Phlorotannins from the brown alga Analipus japonicas. Planta Medica. 1989, 55, 171-175.

39. Koch, M.; Glombitza, K. W.; Eckhard, G. Phlorotannins of Phaeophycea Laminaria ochroleuca. Phytochemistry. 1980, 19, 1821-1823.

40. Glombitza, K. W.; Vogels, H. P. Antibiotics from algae. XXXV. Phlorotannins from Ecklonia maxima. Planta Medica. 1985, 51, 308-312. 
41. Glombitza, K. W.; Rosener, H. U.; Mu"ller, D. Bifuhalol und Diphlorethol aus Cystoseira tamariscifolia. Phytochemistry. 1975, 14, 1115-1116.

42. Glombitza, K. W.; Forster, M.; Eckhardt, G. Polyhydroxyphenyla"ther aus der Phaeophycee Sargassum muticum. Phytochemistry. 1978, 17, 579-580.

43. Grosse-Damhues, J.; Glombitza, K. W. Isofuhalols, a type of phlorotannin from the brown alga Chorda filum. Phytochemistry. 1984, 23, 2639-2642.

44. Glombitza, K. W.; Li, S. M. Hydroxyphlorethols from the brown alga Carpophyllum maschalocarpum. Phytochemistry. 1991, 30, 2741-2745.

45. Yoon, N. Y.; Chung, H. Y.; Kim, H. R.; Choi, J. S. Acetyl- and butyrylcholinesterase inhibitory activities of sterols and phlorotannins from Ecklonia Stolonifera. Fisheries Sci. 2008, 74, 200-207.

46. Yoon, N.Y.; Eom, T. K.; Kim, M. M.; Kim, S. K. Inhibitory effect of phlorotannins isolated from Ecklonia cava on mushroom tyrosinase activity and melanin formation in mouse B16F10 melanoma cells. J Agric Food Chem. 2009, 57, 4124-4129.

47. Lee, S. H.; Yong, L.; Karadeniz, F.; Kim, M. M.; Kim, S. K. $\alpha$-Glucosidase and $\alpha$-amylase inhibitory activities of phloroglucinal derivatives from edible marine brown alga, Ecklonia cava. J Sci Food Agr. 2009, 89, 1552-1558.

48. Glombitza, K. W.; Keusgen, M.; Hauperich, S. Fucophlorethols from the brown algae Sargassum spinuligerum and Cystophora torulosa. Phytochemistry. 1997, 46, 1417-1422.

49. Eom, S. H.; Lee, S. H.; Yoon, N. Y.; Jung, W. K.; Jeon, Y. J.; Kim, S. K.; Lee, M. S.; Kim, Y. M. $\alpha$-Glucosidase- and $\alpha$-amylase-inhibitory activities of phlorotannins from Eisenia bicyclis. J Sci Food Agric. 2012, 92, 2084-2090.

50. Arnold, T. M.; Targett, N. M. Marine tannins: The importance of a mechanistic framework for predicting ecological roles. $J$ Chem Ecol. 2002, 28, 1919-1934.

51. Amsler, C. D.; Fairhead, V. A. Defensive and sensory chemical ecology of brown algae. Adv Bot Res. 2006, 43, 1-91.

52. Waterman, P. G.; Mole, S. In Analysis of phenolic plant metabolites, Blackwell Scientific Publications: Oxford, 1994.

53. Schoenwaelder, M. E. A.; Wiencke, C. Phenolic compounds in the embryo development of several northern hemisphere fucoids. Plant Biology. 2000, 2, 24-33.

54. Schoenwaelder, M. E. A.; Clayton, M. N. Secretion of phenolic substances into the zygote wall and cell plate in embryos of Hormosira and Acrocarpia (Fucales, Phaeophyceae). $J$ Phycol. 1998, 34, 969-980.

55. Peng, S.; Scalbert, A.; Monties, B. Insoluble ellagitannins in Castanea sativa and Quercus petraea woods. Phytochemistry. 1991, 30, 775-778.

56. Appel, H. M. Phenolics in ecological interactions - the importance of oxidation. $J$ Chem Ecol. 1993, 19, 1521-1552.

57. Van Alstyne, K. L.; Pelletreau, K. N. Effects of nutrient enrichment on growth and phlorotannin production in Fucus gardneri embryos. Mar Ecol Prog Ser. 20oo, 206, 33-43.

58. Cronin, G.; Hay, M. E. Effects of light and nutrient availability on the growth, secondary chemistry, and resistance to herbivory of two brown seaweeds. Oikos. 1996, 77, 93-106. 
59. Peckol, P.; Krane, J. M.; Yates, J. L. Interactive effects of inducible defence and resource availability on pholorotannins in the north Atlantic brown alga Fucus esiculosus. Mar Ecol Prog Ser. 1996, 138, 209-217.

6o. Jormalainen, V.; Honkanen, T. Multiple cues for phenotypic plasticity in phlorotannin production of the bladder wrack Fucus esiculosus. Phycologia. 2001, 40, 59-60.

61. Pavia, H.; Brock, E. Extrinsic factors influencing phlorotannin production in the brown alga Ascophyllum nodosum. Mar Ecol Prog Ser. 200o, 193, 285-294.

62. Hammerstro“m, K.; Dethier, M. N.; Duggins, D. O. Rapid phlorotannin induction and relaxation in five Washington kelps. Mar Ecol Prog Ser. 1998, 165, 293-305.

63. Pavia, H.; Cervin, G.; Lindgren, A.; Åberg, P. Effects of UV-B radiation and simulated herbivory on phlorotannins in the brown alga Ascophyllum nodosum. Mar Ecol Prog Ser. 1997, 157, 139-146.

64. Lau-Stanley, C. K.; Qian, P. Y. Phlorotannins and related compounds as larval settlement inhibitors of the tube-building polychaete Hydroides elegans. Mar Ecol Prog Ser. 1997, 159, 219-227.

65. Steinberg, P. D.; Estes, J. A.; Winter, F. C. Evolutionary consequences of food chain length in kelp forest communities. Proc Natl Acad Sci USA. 1995, 92, 8145-8148.

66. Stern, J. L.; Hagerman, A. E.; Steinberg, P. D.; Mason, P. K. Phlorotannin-protein interactions. J Chem Ecol. 1996, 22, 1877-1899.

67. Irelan, C. D.; Horn, M. H. Effects of macrophyte secondary chemicals on food choice and digestive efficiency of Cebidichthys iolaceus (Girard), an herbivorous fish of temperate marine waters. J Exp Mar Biol Ecol. 1991, 153, 179-194.

68. Cheeseman, K. H.; Slater, T. F. An introduction to free radical biochemistry. British Med Bull. 1993, 49, 481-489.

69. Li, Y. J.; Takizawa, H.; Kawada, T. Role of oxidative stresses induced by diesel exhaust particles in airway inflammation, allergy and asthma: their potential as a target of chemoprevention. Inflamm Allergy Drug Targets. 2010, 9, 300-305.

70. Ahn, G. N.; Kim, K. N.; Cha, S. H.; Son, C. B.; Lee, J.; Heo, M. S.; Yeo, I. K.; Lee, N. H.; Jee, Y. H.; Kim, J. S.; Heu, M. S.; Jeon, Y. J. Antioxidant activities of phlorotannins purified from Ecklonia cava on free radical scavenging using ESR and H2O2-mediated DNA damage. Eur Food Res Technol. 2007, 22, 71-79.

71. Kang, K. A.; Lee, K.H.; Chae, S.; Zhang, R.; Jung, M. S.; Lee, Y.; Kim, S. Y.; Kim, H. S.; Joo, H. G.; Park, J. W.; Ham, Y. M.; Lee, N. H.; Hyun, J. W. Eckol isolated from Ecklonia cava attenuates oxidative stress induced cell damage in lung fibroblast cells. FEBS Lett. 2005, 579, 6295-6304.

72. Kang, K. A.; Zhang, R.; Lee, K. H.; Chae, S.; Kim, B. J.; Kwak, Y. S.; Park, J. W.; Lee, N. H.; Hyun, J. W. Protective effect of triphloretheol-A from Ecklonia cava against ionizing radiation in vitro. $J$ Radiat Res. 2006, 47, 61-68.

73. Kang, K. A.; Lee, K. H.; Park, J. W.; Lee, N. H.; Na, H. K.; Surh, Y. J.; You, H. J.; Chung, M. H.; Hyun, J. W. Triphlorethol-A induces heme oxygenase-1 via activation of ERK and NFE2 related factor 2 transcription factor. FEBS Lett. 2007, 581, 2000-2008.

74. Li, Y.; Qian, Z. J.; Ryu, B.; Lee, S. H.; Kim, M. M.; Kim, S. K. Chemical components and 
its antioxidant properties in vitro: an edible marine brown alga, Ecklonia cava. Bioorgan Med Chem. 2009, 17, 1963-1973.

75. Kang, M. C.; Cha, S. H.; Wijesinghe, W. A.; Kang, S. M.; Lee, S. H.; Kim, E. A.; Song, C. B.; Jeon, Y. J. Protective effect of marine algae phlorotannins against AAPH-induced oxidative stress in zebrafish embryo. Food Chem. 2013, 138, 950-955.

76. Park, E.; Ahn, G. N.; Lee, N. H.; Kim, J. M.; Yun, J. S.; Hyun, J. W.; Jeon, Y. J.; Wie, M. B.; Lee, Y. J.; Park, J. W.; Jee, Y. Radioprotective properties of eckol against ionizing radiation in mice. FEBS Lett. 2008, 582, 925-930.

77. Sathya, R.; Kanaga, N.; Sankar, P.; Jeeva, S. Antioxidant properties of phlorotannins from brown seaweed Cystoseira trinodis (Forsskål) C. Agardh. Arab J Chem. 2017, 1O, S2608-S2614.

78. Zhang, R.; Yuen, A. K. L.; Magnusson, M.; Wright, J. T.; Nys, R. de.; Masters, A. F.; Maschmeyer, T. A comparative assessment of the activity and structure of phlorotannins from the brown seaweed Carpophyllum flexuosum. Algal Res. 2018, 29, 130-141.

79. Heo, S. J.; Ko, S. C.; Cha, S. H.; Kang, D. H.; Park, H. S.; Choi, Y. U.; Kim, D.; Jung, W. K.; Jeon, Y. J. Effect of phlorotannins isolated from Ecklonia cava on melanogenesis and their protective effect against photo-oxidative stress induced by UV-B radiation. Toxicol In Vitro. 2009, 23, 1123-1130.

8o. Vo, T. S.; Kim, S. K.; Ryu, B.; Ngo, D. H.; Yoon, N. Y.; Bach, L. G.; Hang, N. T. N.; Ngo, D. N. The Suppressive Activity of Fucofuroeckol-A Derived from Brown Algal Ecklonia stolonifera Okamura on UVB-Induced Mast Cell Degranulation. Mar Drugs. 2018, 16, 1-9.

81. Klervi, L. L.; Gwladys, S.; Celine, C.; Laurence, C.; Stephane, C.; Fanny, G.; Maud, L.; Mayalen, Z.; Fabienne, G.; Nathalie, P.; Valerie, S. P. Sunscreen, antioxidant, and bactericide capacities of phlorotannins from the brown macroalga Halidrys siliquosa. J Appl Phycol. 2016, 28, 3547-3559.

82. Kaplan, S. L.; Mason, Jr. E. O. Management of infections due to antibiotic-resistant Streptococcus pneumonia. Clin Microbiol Rev. 1998, 11, 628-644.

83. Nagayama, K.; Iwamura, Y.; Shibata, T.; Hirayama, I.; Nakamura, T. Bactericidal activity of phlorotannins from the brown alga Ecklonia kurome. J Antimicrob Chemother. 2002, 50, 889-893.

84. Lee, D. S.; Kang, M. S.; Hwang, H. J.; Eom, S. H.; Yang, J. Y.; Lee, M. S.; Lee, W. J.; Jeon, Y. J.; Choi, J. S.; Kim, Y. M. Synergistic effect between dieckol from Ecklonia stolonifera and $\beta$-lactams against methicillin-resistant Staphylococcus aureus. Biotechnol Bioprocess Eng. 2008, 13, 758-764.

85. Eom, S. H.; Kim, D. H.; Lee, S. H.; Yoon, N. Y.; Kim, J. H.; Kim, T. H.; Chung, Y. H.; Kim, S. B.; Kim, Y. M.; Kim, H. W.; Lee, M. S.; Kim, Y. M. In vitro antibacterial activity and synergistic antibiotic effects of phlorotannins isolated from Eisenia bicyclis against methicillin-resistant Staphylococcus aureus. Phytother Res. 2013, 27, 1260-1264.

86. Choi, J. S.; Lee, K.; Hong, Y. K.; Lee, B. B.; Cho, K. K.; Kim, Y. C.; Choi, I. S.; Kim, Y. D. Antibacterial activity of the phlorotannins dieckol and phlorofucofuroeckol-a from Ecklonia cava against Propionibacterium acnes. Bot. Sci. 2014, 92, 425-431.

87. Lee, J. H.; Eom, S. H.; Lee, E. H.; Jung, Y. J.; Kim, HJ.; Jo, M. R.; Son, K. T.; Lee, H. J.; Kim, J. H.; Lee, M. S.; Kim, Y. M. In vitro antibacterial and synergistic effect of phlorotannins 
isolated from edible brown seaweed Eisenia bicyclis against acne-related bacteria. Algae. 2014, 29, 47-55.

88. Lopes, G.; Pinto, E.; Andrade, P. B.; Valentão, P. Antifungal Activity of Phlorotannins against Dermatophytes and Yeasts: Approaches to the Mechanism of Action and Influence on Candida albicans Virulence Factor. PLoS ONE. 2013, 8, e72203.

89. Lee, M. H.; Lee, K. B.; Oh, S. M.; Lee, B. H.; Chee, H. Y. Antifungal activities of dieckol isolated from the marine brown alga Ecklonia cava against Trichophyton rubrum. Food Sci Biotechnol. 2010, 53, 504-507.

90. Ojewole, E.; Mackraj, I.; Naidoo, P.; Govender, T. Exploring the use of novel drug delivery systems for antiretroviral drugs. Eur J Pharm Biopharm. 2008, 70, 697-710.

91. Govender, T.; Ojewole, E.; Naidoo, P. Polymeric nanoparticles for enhancing antiretroviral drug therapy. Drug Deliv. 2008, 15, 493-501.

92. Clavel, F.; Hance, A. J. HIV drug resistance. N Engl J Med. 2004, 35O, 1023-1035.

93. Lee, S. A.; Hong, S. K.; Suh, C. I.; Oh, M. H.; Park, J. H.; Choi, B. W.; Park, S. W.; Paik, S. Y. Anti-HIV-1 efficacy of extracts from medicinal plants. J Microbiol. 2010, 48, 249-252.

94. Tantillo, C.; Ding, J.; Jacobo-Molina, A.; Nanni, R. G.; Boyer, P. L.; Hughes, S. H.; Pauwels, R.; Andries, K.; Janssen, P. A.; Arnold, E. Locations of anti-AIDS drug binding sites and resistance mutations in the three-dimensional structure of HIV-1 reverse transcriptase. Implications for mechanisms of drug inhibition and resistance. J Mol Biol. 1994, 243, 369387.

95. Lipsky, J. J. Antiretroviral drugs for AIDS. Lancet. 1996, 348, 800-803.

96. Ahn, M. J.; Yoon, K. D.; Min, S. Y.; Lee, J. S.; Kim, J. H.; Kim, T. G.; Kim, S. H.; Kim, N. G.; Hu, H.; Kim, J. Inhibition of HIV-1 reverse transcriptase and protease by phlorotannins from the brown alga Ecklonia cava. Biol Pharm Bull. 2004, 27, 544-547.

97. Ahn, M. J.; Yoon, K. D.; Kim, C. Y.; Kim, J. H.; Shin, C. G.; Kim, J. Inhibitory activity on HIV-1 reverse transcriptase and integrase of a carmalol derivative from a brown alga, Ishige okamurae. Phytother Res. 2006, 20, 711-713.

98. Artan, M.; Li, Y.; Karadeniz, F.; Lee, S. H.; Kim, M. M.; Kim, S. K. Anti-HIV-1 activity of phloroglucinol derivative, 6,6-bieckol, from Ecklonia cava. Bioorg Med Chem. 20o8, 16, 7921-7926.

99. Kwon, H. J.; Ryu, Y. B.; Kim, Y. M.; Song, N.; Kim, C. Y.; Rho, M. C.; Jeong, J. H.; Cho, K. O.; Lee, W. S.; Park, S. J. In vitro antiviral activity of phlorotannins isolated from Ecklonia cava against porcine epidemic diarrhea coronavirus infection and hemagglutination. Bioorg Med Chem. 2013, 21, 4706-4713.

100. Arshad, S. H. Does exposure to indoor allergens contribute to the development of asthma and allergy? Curr Allergy Asthma Rep. 2010, 10, 49-55.

101. Milián, E.; Díaz, A. M. Allergy to house dust mites and asthma. P R Health Sci J. 2004, $23,47-57$.

102. Galli, S. J.; Tsai, M.; Piliponsky, A. M. The development of allergic inflammation. Nature. 2008, $454,445-454$.

103. Li, Y.; Lee, S. H.; Le, Q. T.; Kim, M. M.; Kim, S. K. Anti-allergic effects of phlorotannins on histamine release via binding inhibition between IgE and FceRI. $J$ Agric Food Chem. 
2008, 56, 12073-12080.

104. Shim, S. Y.; Choi, J. S.; Byun, D. S. Inhibitory effects of phloroglucinol derivatives isolated from Ecklonia stolonifera on FceRI expression. Bioorg Med Chem. 2009, 17, 4734-4739.

105. Sugiura, Y.; Matsuda, K.; Yamada, Y.; Nishikawa, M,.; Shioya, K.; Katsuzaki, H.; Imai, K.; Amano, H. Isolation of a new anti-allergic phlorotannin, Phlorofucofuroeckol-B, from an edible brown alga, Eisenia arborea. Biosci Biotechnol Biochem. 2006, 70, 2807-2811.

106. Sugiura, Y.; Matsuda, K.; Yamada, Y.; Nishikawa, M.; Shioya, K.; Katsuzaki, H.; Imai, K.; Amano, H. Anti-allergic phlorotannins from the edible brown alga, Eisenia arborea. Food Sci Technol Res. 2007, 13, 54-60.

107. Matsubara, M.; Masaki, S.; Ohmori, K.; Karasawa, A.; Hasegawa, K. Differential regulation of IL-4 expression and degranulation by anti-allergic olopatadine in rat basophilic leukemia (RBL-2H3) cells. Biochem Pharmacol. 2004, 67, 1315-1326.

108. Barbosa, M.; Lopes, G.; Valentão, P.; Ferreres, F.; Gil-Izquierdo, Á.; Pereira, D. M.; Andrade, P. B. Edible seaweeds' phlorotannins in allergy: A natural multi-target approach. Food Chem. 2018, 265, 233-241.

109. Meyer, K. The biological significance of hyaluronic acid and hyaluronidase. Physiol Rev. 1947, 27, 335-359.

110. Kakegawa, H.; Matsumoto, H.; Satoh, T. Inhibitory effects of some natural products on the activation of hyaluronidase and their antiallergic actions. Chem Pharm Bull. 1992, 4O, 1439-1442.

111. Kim, T. W.; Lee, J.H.; Yoon, K. B.; Yoon, D. M. Allergic reactions to hyaluronidase in pain management: A report of three cases. Korean J Anesthesiol. 2011, 6o, 57-59.

112. Shibata, T.; Fujimoto, K.; Nagayama, K.; Yamaguchi, K.; Nakamura, T. Inhibitory activity of brown algal phlorotannins against hyaluronidase. Int J Food Sci Tech. 2002, 37, 703-709.

113. Sugiura, Y.; Matsuda, K.; Yamada, Y.; Imai, K.; Kakinuma, M.; Amano, H. Radical scavenging and hyarulonidase inhibitory activities of phlorotannins from the edible brown alga Eisenia arborea. Food Sci Technol Res. 2008, 14, 595-598.

114. Sugiura, Y.; Matsuda, K.; Okamoto, T.; Yamada, Y.; Imai, K.; Ito, T.; Kakinuma, M.; Amano, H. The inhibitory effects of components from a brown alga, Eisenia arborea, on degranulation of mast cells and eicosanoid synthesis. J Funct Foods. 2oo9, 1, 387-393.

115. Gordon, S. The role of the macrophage in immune regulation. Res Immunol. 1998, 149, 685-688.

116. Gautam, R.; Jachak, S. M. Recent developments in anti-inflammatory natural products. Med Res Rev. 2009, 29, 767-820.

117. Gallin, J. I.; and Snyderman, R. In Overview in Inflammation: Basic Principles and Clinical Correlates, 3rd ed.; Lippincott Williams \& Wilkins: Philadelphia, 1999.

118. Kang, K.; Hwang, H. J.; Hong, D. H.; Park, Y.; Kim, S. H.; Lee, B. H.; Shin, H. C. Antioxidant and antiinflammatory activities of ventol, a phlorotannin-rich natural agent derived from Ecklonia cava, and its effect on proteoglycan degradation in cartilage explant culture. Res Commun Mol Pathol Pharmacol. 2004, 115-116, 77-95.

119. Wijesinghe, W. A. J. P.; Ahn, G.; Lee, W. W.; Kang, M. C.; Kim, E. A.; Jeon, Y. J. Antiinflammatory activity of phlorotannin-rich fermented Ecklonia cava processing by-product 
extract in lipopolysaccharide-stimulated RAW 264.7 macrophages. $J$ Appl Phycol. 2013, 25, 1207-1213.

120. Yang, Y. I.; Shin, H. C.; Kim, S. H.; Park, W. Y.; Lee, K. T.; Choi, J. H. 6,6'-Bieckol, isolated from marine alga Ecklonia cava, suppressed LPS-induced nitric oxide and PGE2production and inflammatory cytokine expression in macrophages: the inhibition of NFkB. Int Immunopharmacol. 2012, 12, 510-517.

121. Kim, A. R.; Lee, M. S.; Choi, J. W.; Utsuki, T.; Kim, J. I.; Jang, B. C.; Kim, H. R. Phlorofucofuroeckol A suppresses expression of inducible nitric oxide synthase, cyclooxygenase-2, and pro-inflammatory cytokines via inhibition of nuclear factor- $\mathrm{kB}$, c-Jun NH2-terminal kinases, and Akt in microglial cells. Inflammation. 2013, 36, 259-271.

122. Kim, A. R.; Shin, T. S.; Lee, M. S.; Park, J. Y.; Park, K. E.; Yoon, N. Y.; Kim, J. S.; Choi, J. S.; Jang, B. C.; Byun, D. S.; Park, N. K.; Kim, H. R. Isolation and identification of phlorotannins from Ecklonia stolonifera with antioxidant and anti-inflammatory properties. $J$ Agric Food Chem. 2009, 57, 3483-3489.

123. Jung, H. A.; Jin, S. E.; Ahn, B. R.; Lee, C. M.; Choi, J. S. Anti-inflammatory activity of edible brown alga Eisenia bicyclis and its constituents fucosterol and phlorotannins in LPSstimulated RAW264.7 macrophages. Food Chem Toxicol. 2013, 59, 199-206.

124. Sugiura, Y.; Tanaka, R.; Katsuzaki, H.; Imai, K.; Matsushita, T. The anti-inflammatory effects of phlorotannins from Eisenia arborea on mouse ear edema by inflammatory inducers. $J$ Funct Foods. 2013, 5, 2019 - 2023.

125. Shibata, T.; Nagayama, K.; Tanaka, R.; Yamaguchi, K.; Nakamura, T. Inhibitory effects of brown algal phlorotannins on phospholipase A2s, lipoxygenases and cyclooxygenases. $J$ Appl Phycol. 2003, 15, 61-66.

126. Yang, Y. I.; Woo, J. H.; Seo, Y. J.; Lee, K. T.; Lim, Y.; Choi, J. H. Protective Effect of Brown Alga Phlorotannins against Hyper-inflammatory Responses in LipopolysaccharideInduced Sepsis Models. J Agric Food Chem. 2016, 64, 570-578.

127. Barbosa, M.; Lopes, G.; Ferreres, F.; Andrade, P. B.; Pereira, D. M.; Gil-Izquierdo, Á.; Valentão, P. Phlorotannin extracts from Fucales: Marine polyphenols as bioregulators engaged in inflammation-related mediators and enzymes. Algal Res. 2017, 28, 1-8.

128. Hail, Jr. N. Mitochondria: a novel target for the chemoprevention of cancer. Apoptosis. 2005, 10, 687-705.

129. Reddy, L.; Odhav, B.; Bhoola, K. D. Natural products for cancer prevention: a global perspective. Pharmacol. Ther. 2003, 99, 1- 13 .

130. Nirmala, M. J.; Samundeeswari, A.; Sankar, P. D. Natural plant resources in anti-cancer therapy-A review. Res Plant Biol. 2011, 1, 01-14.

131. Bhanot, A.; Sharma, R.; Noolvi, M. N. Natural sources as potential anti-cancer agents: A review. Int $J$ Phytomedicine. 2011, 3, 09-26.

132. Kong, C. S.; Kim, J. A.; Yoon, N. Y.; Kim, S. K. Induction of apoptosis by phloroglucinol derivative from Ecklonia cava in MCF-7 human breast cancer cells. Food Chem Toxicol. 2009, $47,1653-1658$.

133. Nwosu, F.; Morris, J.; Lund, V. A.; Stewart, D.; Ross, H. A.; McDougall, G. J. Antiproliferative and potential anti-diabetic effects of phenolic-rich extracts from edible marine algae. Food Chem. 2011, 126, 1006-1012. 
134. Namvar, F.; Mohamad, R.; Baharara, J.; Zafar-Balanejad, S.; Fargahi, F.; Rahman, H. S. Antioxidant, antiproliferative, and antiangiogenesis effects of polyphenol-rich seaweed (Sargassum muticum). Biomed Res Int. 2013, 604787.

135. Parys, S.; Kehraus, S.; Krick, A.; Glombitza, K. W.; Carmeli, S.; Klimo, K.; Gerhäuser, C.; König, G. M. In vitro chemopreventive potential of fucophlorethols from the brown alga Fucus vesiculosus L. by anti-oxidant activity and inhibition of selected cytochrome P450 enzymes. Phytochemistry. 2010, 71, 221-229.

136. Kim, M. M.; Ta, Q. V.; Mendis, E.; Rajapakse, N.; Jung, W. K.; Byun, H. G.; Jeon, Y. J.; Kim, S. K. Phlorotannins in Ecklonia cava extract inhibit matrix metalloproteinase activity. Life Sci. 2006, 79, 1436-1443.

137. Alghazeer, R.; Howell, N.; El-Naili, M.; Awayn, N. Anticancer and Antioxidant Activities of Some Algae from Western Libyan Coast. Nat Sci. 2018, 10, 232-246.

138. Casas, M. P.; Rodríguez-Hermida, V.; Pérez-Larrán, P.; Conde, E.; Liveri, M. T.; Ribeiro, D.; Fernandes, E.; Domínguez, H. In vitro bioactive properties of phlorotannins recovered from hydrothermal treatment of Sargassum muticum. Sep Purif Technol. 2016, 167, 117-126.

139. Thilagam, E.; Parimaladevi, B.; Kumarappan, C.; and Mandal, S. C. $\alpha$-Glucosidase a-amylase inhibitory activity of Senna surattensis. J Acupunct Meridian Stud. 2013, 6, 2430 .

140. Rengasamy, K. R.; Aderogba, M. A.; Amoo, S. O.; Stirk, W. A.; Van Staden, J. Potential antiradical and $\alpha$-glucosidase inhibitors from Ecklonia maxima (Osbeck) Papenfuss. Food Chem. 2013, 141, 1412-1415.

141. Kellogg, J.; Grace, M. H.; Lila, M. A. Phlorotannins from Alaskan seaweed inhibit carbolytic enzyme activity. Mar Drugs. 2014, 12, 5277-5294.

142. Okada, Y.; Ishimaru, A.; Suzuki, R.; Okuyama, T. A new phloroglucinol derivative from the brown alga Eisenia bicyclis: Potential for the effective treatment of diabetic complications. J Nat Prod. 2004, 67, 103-105.

143. Moon, H. E.; Islam, N.; Ahn, B. R.; Chowdhury, S. S.; Sohn, H. S.; Jung, H. A.; Choi, J. S. Protein tyrosine phosphatase $1 \mathrm{~B}$ and $\alpha$-glucosidase inhibitory phlorotannins from edible brown algae Ecklonia stolonifera and Eisenia bicyclis. Biosci Biotechnol Biochem. 2011, 75, 1472-1480.

144. Iwai, K. Antidiabetic and antioxidant effects of polyphenols in brown alga Ecklonia stolonifera in genetically diabetic KK-Ay mice. Plant Foods Hum Nutr. 2oo8, 63, 163-169.

145. Jung, H. A.; Yoon, N. Y.; Woo, M. H.; Choi, J. S. Inhibitory activities of extracts from several kinds of seaweeds and phlorotannins from the brown alga Ecklonia stolonifera on glucose-mediated protein damage and rat lens aldose reductase. Fish Sci. 2oo8, 74, 13631365 .

146. Lee, S. H.; Park, M. H.; Heo, S. J.; Kang, S. M.; Ko, S. C.; Han, J. S.; Jeon, Y. J. Dieckol isolated from Ecklonia cava inhibits a-glucosidase and $\alpha$-amylase in vitro and alleviates postprandial hyperglycemia in streptozotocin-induced diabetic mice. Food Chem Toxicol. 2o10, $48,2633-2637$.

147. Kim, E. B.; Nam, Y. H.; Kwak, J. H.; Kang, T. H. Anti-diabetic activity of phlorotannin from Eisenia bicyclis in Zebrafish, a model of type 1 and 2 diabetes. Planta Med. 2015, 81, PW_112. 
148. Park, S. R.; Kim, J. H.; Jang, H. D.; Yang, S. Y.; Kim, Y. H. Inhibitory activity of minor phlorotannins from Ecklonia cava on a-glucosidase. Food Chem. 2018, 257, 128-134.

149. Kaila, B.; and Raman, M. Obesity: a review of pathogenesis and management strategies. Can J Gastroentero. 2008, 22, 61-68.

150. Jung, H. A.; Jung, H. J.; Jeong, H. Y.; Kwon, H. J.; Ali, M. Y.; Choi, J. S. Phlorotannins isolated from the edible brown alga Ecklonia stolonifera exert anti-adipogenic activity on 3T3-L1 adipocytes by downregulating C/EBPa and PPAR $\gamma$. Fitoterapia. 2014, 92, 260-269.

151. Ko, S. C.; Lee, M.; Lee, J. H.; Lee, S. H.; Lim, Y.; and Jeon, Y. J. Dieckol, a phlorotannin isolated from a brown seaweed, Ecklonia cava, inhibits adipogenesis through AMP-activated protein kinase (AMPK) activation in $3 \mathrm{~T} 3$-L1 preadipocytes. Environ Toxicol Pharmacol. 2013, 36, 1253-1260.

152. Park, M. H.; Jeon, Y. J.; Kim, H. J.; Han, J. S. Effect of diphlorethohydroxycarmalol isolated from Ishige okamurae on apoptosis in 3t3-L1 preadipocytes. Phytother Res. 2013, 27, 931-936.

153. Mori, T.; Hidaka, M.; Ikuji, H.; Yoshizawa, I.; Toyohara, H.; Okuda, T.; Uchida, C.; Asano, T.; Yotsu-Yamashita, M.; Uchida, T. A high-throughput screen for inhibitors of the prolyl isomerase, Pin1, identifies a seaweed polyphenol that reduces adipose cell differentiation. Biosci Biotechnol Biochem. 2014, 78, 832-838.

154. Ahn, G.; Park, E.; Park, H. J.; Jeon, Y. J.; Lee, J.; Park, J. W.; Jee, Y. The classical NF-kB pathway is required for phloroglucinol-induced activation of murine lymphocytes. Biochimi Biophys Act. 2010, 180o, 639-645.

155. Wijesinghe, W. A Ko, S. C.; Jeon, Y. J. Effect of phlorotannins isolated from Ecklonia cava on angiotensin I-converting enzyme (ACE) inhibitory activity. Nutr Res Pract. 2011, $5,93-100$.

156. Jung, H. A.; Hyun, S. K.; Kim, H. R.; Choi, J. S. Angiotensin-converting enzyme I inhibitory activity of phlorotannins from Ecklonia stolonifera. Fish. Sci. 2006, 72, 12921299.

157. Um, M. Y.; Lim, D. W.; Son, H. J.; Cho, S.; Lee, C. Phlorotannin-rich fraction from Ishige foliacea brown seaweed prevents the scopolamine-induced memory impairment via regulation of ERK-CREB-BDNF pathway. $J$ Funct Foods, 2018, 4O, 110-116.

158. Cha, S. H.; Heo, S. J.; Jeon, Y. J.; Park, S. M. Dieckol, an edible seaweed polyphenol, retards rotenone-induced neurotoxicity and $\alpha$-synuclein aggregation in human dopaminergic neuronal cells. RSC Adv. 2016, 6, 110040-110046.

159. Wang, J.; Zheng, J.; Huang, C.; Zhao, J.; Lin, J.; Zhou, X.; Naman, C. B.; Wang, N.; Gerwick, W. H.; Wang, Q.; Yan, X.; Cui, W.; He, S. Eckmaxol, a Phlorotannin Extracted from Ecklonia maxima, Produces Anti- $\beta$-amyloid Oligomer Neuroprotective Effects Possibly via Directly Acting on Glycogen Synthase Kinase 3 $\beta$. ACS Chem Neurosci. 2018, 9, 1349-1356. 